\title{
REMARKABLE IMPROVEMENT OF NOX-PM TRADE-OFF IN A DIESEL ENGINE BY MEANS OF BIO-ETHANOL AND EGR
}

\author{
Masahiro Ishida ${ }^{1}$, Shohei Yamamoto ${ }^{1}$, Hironobu Ueki ${ }^{2}$ and Daisaku Sakaguchi ${ }^{1}$
}

1. Graduate School of Science and Technology, Nagasaki University, 1-14 Bunkyo-machi, Nagasaki 852-8521, Japan;

Ishida $<$ hiro@nagasaki-u.ac.jp $>$, Yamamoto $<$ shohei@tfl.mech.nagasaki-u.ac.jp $>$, Sakaguchi<daisaku@nagasaki-u.ac.jp $>$

2. Faculty of Engineering, Nagasaki University, Japan;

Ueki<ueki@nagasaki-u.ac.jp >

\begin{abstract}
In order to realize a premixed compression ignition (PCI) engine, the effects of bioethanolgas oil blends and exhaust gas recirculation (EGR) on PM-NOx trade-off have been investigated focusing on ignition delay, premixed combustion, diffusion combustion, smoke, NOx and thermal efficiency. The present experiment was done by increasing the ethanol blend ratio and ethanol and by increasing the EGR ratio in a single cylinder direct injection diesel engine. It is found that a remarkable improvement in NOx-PM trade-off can be achieved by promoting the premixing based on the ethanol blend fuel having low evaporation temperature, large latent heat and low cetane number as well, in addition, based on a marked elongation of ignition delay due to the low cetane number fuel and the low oxygen intake charge. As a result, very low levels of NOx and PM, which satisfies the 2009 emission standards imposed on heavy duty diesel engines in Japan, were achieved without deterioration of brake thermal efficiency in the PCI engine fuelled with the 50\% ethanol blend diesel fuel and the high EGR ratio. It is noticed that smoke can be reduced even by increasing the EGR ratio under the highly premixed condition.
\end{abstract}

KEYWORDS: PCI engine, Bio-ethanol, EGR, PM-NOx trade-off

\section{INTRODUCTION}

Recent researches have shown that a HCCI engine or a PCI engine will be a promising way to accomplish almost zero emissions in NOx and PM. In order to achieve the severe emission standards imposed on diesel engines such as the post new-long term emission standards for 2009 in Japan, the EURO VI standards for 2012 and the US standards for 2010, it is necessary not only to depend upon the aftertreatment system installed with NOx catalyst and PM catalyst but also to suppress formations of NOx and PM in the spray combustion process by forming the HCCI or PCI condition.

A dual fuel diesel engine, a kind of HCCI engine, fuelled with natural gas (NG) and ignited by a small amount of gas oil was investigated to reduce both NOx and particulate emissions simultaneously by Kusaka, et al. ${ }^{[1]}$, Ishida, et al. ${ }^{[2]}$, Tagai, et al. ${ }^{[3]}$ and Saito, et al. ${ }^{[4]}$ previously, and also studied by Carlucci, A. P., et al. ${ }^{[5]}$ and Papagiannakis, R. G., et al. ${ }^{[6]}$ recently. A similar dual fuel engine fuelled with methanol and assisted by a small amount of gas oil was tested by 
the authors ${ }^{[7-9]}$. As a result, a significant improvement in the trade-off between NOx and PM was achieved without deteriorating the thermal efficiency by means of the premixed charge under the conditions of a minimum amount of gas oil for stable ignition and EGR as well. A direct injection diesel engine fuelled with dimethyl ether (DME) was also investigated for low emission diesel engines by Kajitani, S. et al. ${ }^{[10,11]}$ and Ohmura, T., et al. ${ }^{[12]}$, however, the HCCI engine fuelled with DME alone showed some problems associated with the ignition timing control, the large amount of unburned hydrocarbon emission, and the limited load operation range due to misfire and knock. Then, HCCI engines fuelled with composite fuel of DME and natural gas were investigated by Chen, et al. ${ }^{[13,14]}$, Konno, et al. ${ }^{[15]}$, Iida, et al. ${ }^{[16]}$ and Ishida, et al. ${ }^{[17-20]}$, and the effects of intake temperature, compression ratio and EGR ratio on the low temperature reaction (LTR) and the high temperature reaction (HTR), misfire limit, knock limit, exhaust emissions and thermal efficiency were clarified. A similar HCCI combustion fuelled with DME and methanol was investigated by Ishida et al. ${ }^{[21]}$, a HCCI combustion fuelled with a vaporized diesel fuel was examined by Ganesh, et al. ${ }^{[22]}$ and a partial HCCI combustion based on early direct injection of diesel fuel was studied by García, et al. ${ }^{[23]}$. Another HCCI engine fuelled with hydrogen and carbon monoxide reformed from DME was investigated by Shudo, et al. ${ }^{[24,25]}$ and the one fuelled with the reformed gas from biodiesel and bioethanol was investigated by Tsolakis et al. ${ }^{[26]}$ respectively. It was shown that both natural gas and methanol have a strong effect on suppression of the LTR of DME, and the HTR is retarded properly to near TDC, resulting in a high degree of constant volume combustion. The effect of EGR was focused on improvement in the brake thermal efficiency of a HCCI engine in the authors' studies ${ }^{[18,20]}$, and it was noticed that the increment of $4 \%$ in brake thermal efficiency was achieved by the high EGR ratio of 0.5 compared with the case without EGR. The increase in brake thermal efficiency due to EGR was based on improvement of combustion efficiency mainly resulting from a significant reduction in the unburned hydrocarbon emission. Another focus was put on the achievable highest load in a HCCI engine. Consequently, it was found that the highest load could be achieved under the condition with the minimum DME amount for stable ignition, however, the achieved highest load was limited up to about $0.45 \mathrm{MPa}$ in any studies.

As mentioned in the above, HCCI engines showed an important problem on the limited load range due to misfire and knock, then, a premixed compression ignition (PCI) engine was thought to be better to expand the engine load range. In recent studies on the PCI engine operated with a low cetane number fuel, adopting a high EGR ratio, Ogawa et al. ${ }^{[27]}$ and Li et al. ${ }^{[28,29]}$ showed experimentally that smoke emission could be decreased drastically by large quantities of cooled EGR and low cetane number fuels, and smoke was dependent strongly upon a long enough ignition delay, in other words, the premixing time between the end of fuel injection and the onset of ignition. It is clear that this low emission could be achieved by the low temperature combustion based on the ultra-high EGR ratio. Ishida et al. ${ }^{[30]}$ showed the effectiveness of gasoline-diesel fuel blends in a diesel engine experimentally, and smoke was reduced markedly by increasing the gasoline blend ratio because ignition delay was elongated due to the gasoline properties with low cetane number and low evaporation temperature.

Similarly, ethanol as a carbon neutral fuel should be noticed as another fuel with low cetane number and low evaporation temperature. Combustion tests on bio-ethanol was done by Kamio et al. ${ }^{[31]}$ in HCCI-SI hybrid combustion, and the effect of water on bio-ethanol HCCI combustion was investigated by Megaritis et al. ${ }^{[32]}$ and Mack et al. ${ }^{[33]}$. On the other hand, Rakopoulos et al. $^{[34]}$ has done combustion analysis in a diesel engine fuelled with $15 \%$ ethanol-diesel fuel blends. The objective of the present study is to show a feasibility of a PCI engine for achieving extremely low PM and NOx by adopting bioethanol-gas oil blends in combination with EGR. The gas oil blended with bio-ethanol was burned in a diesel engine, and the effects of the ethanol 
blend ratio and the EGR ratio on ignition delay, premixed combustion, diffusion combustion, smoke density, concentrations of NOx, unburned hydrocarbon and carbon monoxide, and the brake thermal efficiency were investigated in detail.

\section{NOMENCLATURE}

ATDC After top dead center

be $\quad$ Brake specific fuel consumption $[\mathrm{MJ} / \mathrm{kWh}]$

BTDC Before top dead center

CA Crank angle

$\mathrm{CO} \quad$ Carbon monoxide emission $[\mathrm{ppm}]$ or $[\mathrm{g} / \mathrm{kWh}]$

CA50 50\% burnt point [deg.CA ATDC]

$\mathrm{CO}_{2} \quad \mathrm{CO}_{2}$ concentration [\%]

$\mathrm{dQ} / \mathrm{d} \theta \quad$ Net heat release rate $[\mathrm{J} /$ degree $]$

EGR Exhaust gas recirculation

EtOH30 Blend fuel with $68 \mathrm{vol} \%$ gas oil, $29 \mathrm{vol} \%$ ethanol and $3 \mathrm{vol} \%$ octanol

EtOH50 Blend fuel with $48 \mathrm{vol} \%$ gas oil, $48 \mathrm{vol} \%$ ethanol and $4 \mathrm{vol} \%$ octanol

HCCI Homogeneous charge compression ignition

HTR High temperature reaction

$\mathrm{Hu} \quad$ Lower heating value of fuel $[\mathrm{J} / \mathrm{mg}]$

Lift Needle valve lift [mm]

LTR Low temperature reaction

$\mathrm{m}_{\mathrm{d}} \quad$ Mass rate of diffusion combustion [mg/cycle]

NOx Nitrogen oxides emission $[\mathrm{ppm}]$ or $[\mathrm{g} / \mathrm{kWh}]$

$\mathrm{p}_{\mathrm{me}} \quad$ Brake mean effective pressure $[\mathrm{MPa}]$

$\mathrm{P} \quad$ In-cylinder pressure [MPa]

PCI Premixed compression ignition

PM Particulate matter [mg/cycle] or $[\mathrm{g} / \mathrm{kWh}]$

$\mathrm{Q}_{\text {total }} \quad$ Total cumulative heat release [J/cycle]

$\mathrm{Q}_{\mathrm{d}} \quad$ Cumulative heat release of diffusion combustion [J/cycle]

$\mathrm{Q}_{\mathrm{p}} \quad$ Cumulative heat release of premixed combustion [J/cycle] ( $\left.=\mathrm{Q}_{\text {total }}-\mathrm{Q}_{\mathrm{d}}\right)$

Smoke Smoke density [Bosch]

THC Total unburned hydrocarbon emission $[\mathrm{ppm}]$ or $[\mathrm{g} / \mathrm{kWh}]$

$\mathrm{T} \quad$ Temperature $\left[{ }^{\circ} \mathrm{C}\right]$

$\mathrm{X}_{\mathrm{EGR}} \quad$ EGR ratio (approximated by $\mathrm{CO}_{2 \mathrm{IN}} / \mathrm{CO}_{2 \mathrm{Exh}}$ )

$\theta \quad$ Crank angle [degree]

$\theta_{\text {inj }}$ Injection timing [deg.CA BTDC]

$\varepsilon \quad$ Compression ratio

Subscripts

$0 \quad$ Without EGR

e, Exh Exhaust gas

IN Intake charge

\section{EXPERIMENTAL APPARATUS AND MEASUREMENTS}

The test engine was a single cylinder high-speed naturally aspirated direct injection diesel engine, the type NFD 170-(E) manufactured by YANMAR Co., Ltd. Figure 1(a) shows the 
section of test engine with a horizontal cylinder axis. Piston is a conventional one with toroidal cavity. The bore is $102 \mathrm{~mm}$, the stroke is $105 \mathrm{~mm}$, and the compression ratio is $\varepsilon=17.8$. Fuel injection pump is the conventional type Bosch PFR-1AW with $9 \mathrm{~mm}$ plunger dia. Principal particulars of the test engine is shown in Table 1. Figure 1(b) shows the combustion test system. The suction air pressure at the intake manifold was always adjusted at the standard atmosphere pressure of $0.1013 \mathrm{MPa}$ by using the electric blower. Intake charge temperature was kept constant at $\mathrm{T}_{\mathrm{IN}}=40 \pm 0.5^{\circ} \mathrm{C}$ by using electric heater installed upstream of mixing chamber and EGR cooler was used in the case with EGR, that is, the cooled EGR was adopted. EGR gas was charged into the mixing chamber located at $1,800 \mathrm{~mm}$ upstream of the intake manifold. Air flow rate was measured by using entrance nozzle installed in the plenum tank located upstream of surge tank. In order to calculate the fuel flow rate, a weight decrement of fuel tank was measured in the specified time interval of ten minutes by the electronic weighing instrument. The combustion tests were carried out at a constant engine speed of $1,200 \pm 5 \mathrm{rpm}, 50 \%$ of the rated speed. Engine load was controlled by the electrical dynamometer, measuring shaft torque and rotational speed, and it was changed from $20 \%$ load $\left(\mathrm{p}_{\mathrm{me}}=0.13 \mathrm{MPa}\right)$ to $80 \%$ load $(0.51 \mathrm{MPa})$, which correspond to equivalence ratios of 0.19 and 0.53 in the cases without EGR. The fuel was injected into the combustion chamber directly at a constant injection timing of $5 \pm 0.2$ deg.CA BTDC, however at the final experiment, it was advanced to $14 \pm 0.2$ deg.CA BTDC to achieve better NOx-PM trade-off. The test conditions are summarized in Table 2.

Test fuels are low sulfur diesel fuel (gas oil JIS \#2 in Japan) having cetane number of 55 and ethanol with that of about 8 . Properties of tested fuels are summarized in Table 3 . The blend fuel named EtOH30 consists of $68 \mathrm{vol} \%$ gas oil, 29 vol\% ethanol with $3 \mathrm{vol} \%$ octanol as a surfaceactive agent, and EtOH50 consists of $48 \%$ gas oil, $48 \%$ ethanol and $4 \%$ octanol. The solubility between gas oil and ethanol was examined at three kinds of fuel temperature as shown in Fig.2, and the minimum amount of octanol for a stable blend fuel without phase separation was determined experimentally for various ethanol blend ratios. The lower heating value of ethanol $26.8 \mathrm{MJ} / \mathrm{kg}$ is fairly smaller compared to that of gas oil $42.9 \mathrm{MJ} / \mathrm{kg}$. Ethanol has lower cetane number, lower evaporation temperature and larger latent heat compared with gas oil, and the cetane number of the blend fuel shown in Table 3 was estimated from the volume ratio between ethanol and gas oil.

The exhaust gas temperature was measured by means of the E-type thermocouple at the exhaust manifold, and temperatures of fuel, air, cooling water and intake charge were measured by the T-type thermocouple. $\mathrm{CO}_{2}$ concentration was measured at both intake and exhaust manifolds respectively to calculate the EGR ratio approximately. In the exhaust gas analysis, exhaust gas temperature $\mathrm{Te}$, concentrations of carbon monoxide $\mathrm{CO}$, total unburned hydrocarbon THC and nitrogen oxides NOx, and smoke density were measured by means of respective sensor. Table 4 shows summary of equipment, detection principle, and accuracy of measurements. The time-history of in-cylinder pressure and the needle valve lift were measured by using the piezoelectric pressure transducer and gap sensor simultaneously and the outputs were sampled every one-fourth degree in crank angle by means of the 4 channel combustion analyzer CB-467 manufactured by Ono Sokki Co. Ltd. The time-history of combustion pressure was the ensemble average sampled over continuous 350 engine cycles. The data were transmitted to the personal computer and recorded on hard disks. 


\section{RESULTS AND DISCUSSION}

\subsection{Effects of Ethanol Blend Ratio and EGR Ratio on Combustion Time-History and Engine Performance}

Figures 3(a), (b) and (c) show changes in time-history of combustion due to ethanol blend, EGR and engine load as well respectively. The abscissa denotes the crank angle $\theta$ deg.CA, and the ordinates denote the measured in-cylinder pressure $\mathrm{P}$, the rate of net heat release $\mathrm{dQ} / \mathrm{d} \theta$ and the needle valve lift respectively. In the experiment, the injection timing was set at $5 \pm 0.2 \mathrm{deg}$.CA BTDC as shown in the lift curves, and the intake charge temperature was kept constant at $40{ }^{\circ} \mathrm{C}$ even in the case with EGR by means of the cooled EGR system. As the ethanol blend ratio increases and also the EGR ratio increases, as shown in Figs.3(a) and (c), the ignition timing is retarded and the ignition delay becomes larger markedly especially in the case of EtOH50, on the other hand, the end of combustion was not retarded. And the premixed combustion increases and the diffusion combustion decreases remarkably. As the engine load increases in the case of EtOH50, the heat release rates in both premixed combustion and diffusion combustion increase but ignition delay is almost unchanged as shown in Fig.3(b). It should be noticed that, in the case of EtOH50 having low cetane number and low evaporation temperature, ignition occurs after the end of fuel injection at low loads such as $\mathrm{p}_{\mathrm{me}}=0.13$ and $0.26 \mathrm{MPa}$.

Figure 4 shows changes in exhaust emissions and fuel consumption due to engine load, where the parameters are the fuel and the EGR ratio. The engine load "p me" was increased by increasing the injection amount of blend fuel at each EGR ratio. The brake specific fuel consumption "be[g/kWh]" in usual was reduced to "be[MJ/kWh]" by compensating the lower heating value of each fuel, and they show almost equal fuel consumption between three cases, however, the one of EtOH50 is a little higher in the low loads and a little lower in the high loads compared with the one of gas oil alone. The higher fuel consumption in the low load results from increases in $\mathrm{CO}$ emission and THC emission due to too much lean burn condition with the equivalence ratio of $0.20-0.29$. On the other hand, the lower fuel consumption in the high load results from a little earlier end of combustion as shown in Fig.3(a). NOx increases a little by ethanol blend because the premixed combustion increases due to longer ignition delay and lower evaporation temperature, and it is reduced markedly by EGR as shown in Fig.4. Smoke density in the case of EtOH50 is reduced remarkably over the load operation range, in addition, it is decreased further by EGR. Especially in the low loads, smoke density becomes almost zero due to promotion of the premixing resulting from late ignition after the end of fuel injection ${ }^{[27]}$ as shown in Fig.3(b).

Figure 5 shows the NOx reduction rate due to EGR and Fig. 6 shows smoke change rate due to EGR. It is reasonable that NOx decreases remarkably as the EGR ratio increases, and about $90 \%$ reduction in NOx was achieved by the EGR ratio of 0.5 . It should be noticed that, only in the case of EtOH50, smoke was reduced by increasing the EGR ratio. The reason why it was reduced by EGR will be clearly shown in the latter section of this paper.

\subsection{Elongation of Ignition Delay due to Ethanol and EGR}

Definitions of ignition timing, ignition delay, the premixed combustion and the approximated diffusion combustion are shown in the heat release rate curve calculated from the experimental pressure history. In Fig.7, the ignition timing was defined as the zero-cross point of the dotted line tangential to the heat release rate curve in the initial premixed combustion stage. The ignition delay was defined as the crank angle duration between the start of injection and the ignition point. The heat release rate curve during the diffusion combustion period was approximated by the Wiebe function ${ }^{[35]}$ between the second peak of the heat release curve and 
the end of combustion. In the present analysis, it was assumed that the diffusion combustion begins at the maximum heat release timing in the premixed combustion, which is a similar procedure in the two zone model analysis by the authors ${ }^{[36,37]}$. The cumulative heat release rate of diffusion combustion $Q_{d}$ was calculated by integrating the Wiebe function, and the premixed combustion quantity $Q_{p}$ was calculated by subtracting $Q_{d}$ from the total cumulative heat release $\mathrm{Q}_{\text {total. }}$ Figure 8 shows an uncertainty of diffusion combustion index " $\mathrm{m}$ " of Wiebe function in relation to diffusion combustion quantity $\mathrm{Q}_{\mathrm{d}}$. The tendency that the index $\mathrm{m}$ decreases as $\mathrm{Q}_{\mathrm{d}}$ increases is quite reasonable although showing some inevitable scattering.

Figure 9 shows variation of ignition delay due to the EGR ratio, where the parameters are the fuel and the engine load. The ignition delay is dependent basically upon the fuel cetane number; the cetane number of the tested fuels varies from 55 of gas oil to 41 of the fuel EtOH30 and 32 of the fuel EtOH50. In the ethanol blend fuels, ignition delay increases mainly based on the low cetane number and secondarily based on the large latent heat and the low evaporation temperature as well. The lower the cetane number, the longer the ignition delay is, and it also increases more by increasing the EGR ratio. However, variation of ignition delay due to engine load is relatively small except for the cases with a high EGR ratio near misfire limit. Figure 10 shows the correlation between the ignition delay and the oxygen concentration in the intake charge mainly dominated by the EGR ratio. The plotted data are the same ones shown in Fig.9, and they are separated into three groups clearly depending on the fuel cetane number. The rate of increase in ignition delay due to decrease in oxygen concentration is much larger in the lower cetane number fuel, in other words, the so-called dilution effect ${ }^{[32]}$ in the intake charge due to EGR appears markedly on the low cetane number fuel. As a result, the premixing can be promoted more in the lower cetane number fuel under a high EGR condition, of course, in the fuel with lower evaporation temperature.

Figures 11(a) and (b) show the relationship between the premixed combustion quantity $Q_{p}$ and the amount of heat input, in which $\mathrm{Q}_{\mathrm{p}}$ consists of combustion of gas oil and/or ethanol; (a) shows comparison of $Q_{p}$ between the three fuels, and (b) shows the relation between $Q_{p}$ and the amount of injected ethanol heat. As shown in Fig.11(a), the premixed combustion $Q_{p}$ based on gas oil alone is almost unchanged by the heat input, or, the engine load. On the other hand, as shown in Fig.11(b), $Q_{p}$ based on ethanol combustion increases almost linearly with the amount of injected ethanol heat. In other words, the premixing can be promoted significantly by increasing the ethanol blend ratio. Figure 12 shows the relation between $\mathrm{Q}_{\mathrm{p}} / \mathrm{Q}_{\text {total }}$ and $\mathrm{NOx}$, where the parameters are the fuel and the engine load, and the data with different EGR ratio are indicated by the same symbol mark. As the EGR ratio increases, $Q_{\text {total }}$ varies little at the specified load but $\mathrm{Q}_{\mathrm{p}}$ becomes large. In this case, NOx decreases drastically while $\mathrm{Q}_{\mathrm{p}} / \mathrm{Q}_{\mathrm{total}}$ increases. As shown in Fig.12, $Q_{p}$ of the low cetane number fuel EtOH50 becomes about twice compared with that of gas oil, however, the increase in NOx is small. It is clear that NOx is not always dependent on the premixed combustion in the present experiment. Generally, NOx increases as the premixed combustion increases because the larger premixed combustion results in the higher combustion pressure, then, the higher combustion temperature. However, as the ethanol blend ratio increases, PCI combustion approaches to HCCI combustion due to promotion of the premixing, then, the high temperature region in the spray combustion becomes small, resulting in suppression of NOx formation rate.

\subsection{Relationship between Diffusion Combustion and PM}

Figure 13 shows change in the cumulative heat release $Q_{d}$ during diffusion combustion due to ignition delay, where the parameter is the engine load $\mathrm{p}_{\mathrm{me}}$. The data in the figure include the cases with different ethanol blend ratio and the cases with different EGR ratio. $Q_{d}$, which seems 
to be a main factor of smoke emission, decreases almost linearly with increase in ignition delay at any engine load while $Q_{d}$ is larger at the higher load because of the larger amount of injected fuel.

The mass rate of diffusion combustion " $\mathrm{m}_{\mathrm{d}}$ " was calculated by the following equation;

$$
\mathrm{m}_{\mathrm{d}}=\mathrm{Q}_{\mathrm{d}} / \mathrm{Hu}
$$

where $\mathrm{Hu}$ is the lower heating value of the fuel.

Assuming that all ethanol burns in the premixed combustion stage, and composition in gas oil having higher evaporation temperature burns in the diffusion combustion process because ethanol has fairly low evaporation temperature compared with gas oil, the lower heating value of gas oil was adopted for $\mathrm{Hu}$ in Eq.(1). Figure 14 shows a correlation between the mass rate of diffusion combustion $\mathrm{m}_{\mathrm{d}}$ and the injection quantity of gas oil. All $\mathrm{Q}_{\mathrm{d}}$ data shown in Fig.13 are plotted again in Fig.14. It is clear that $m_{d}$ correlates well with the injection quantity of gas oil, in other words, $\mathrm{m}_{\mathrm{d}}$ is strongly dependent upon injection quantity of gas oil and it is about $70 \%$ of the injected gas oil.

Figure 15 shows the relationship between the particulate matter "PM" in the exhaust gas and the diffusion combustion mass " $\mathrm{m}_{\mathrm{d}}$ ", where the parameter is the EGR ratio " $\mathrm{X}_{\mathrm{EGR}}$ ". Figure 16 shows the relationship between PM and the diffusion combustion mass parameter " $\mathrm{m}_{\mathrm{d}} /\left(1-\mathrm{X}_{\mathrm{EGR}}\right)$ ". PM is dependent on both factors of $m_{d}$ and $X_{E G R}$ as shown in Fig.15, however, it is dependent on the unique factor of $m_{d} /\left(1-X_{E G R}\right)$ as shown in Fig. 16. The factor of $\left(1-X_{E G R}\right)$ represents the fraction of fresh intake air in the intake charge, then, $\mathrm{m}_{\mathrm{d}} /\left(1-\mathrm{X}_{\mathrm{EGR}}\right)$ means the diffusion combustion mass per unit fresh air, in other words, a kind of fuel/air ratio like. If the EGR ratio is constant, PM increases as $m_{d}$ increases, and also PM increases as the EGR ratio increases if $m_{d}$ is constant. It cannot be simply determined whether the PM decreases or increases because variation of $m_{d}$ is dependent strongly upon ignition delay. In order to reduce PM at the time when the EGR ratio increases, the value of $\mathrm{m}_{\mathrm{d}} /\left(1-\mathrm{X}_{\mathrm{EGR}}\right)$ should become smaller, for instance, as shown in Fig. 16 by two solid circles on the correlation line. This condition is written by the following equation;

$$
\mathrm{m}_{\mathrm{d}} /\left(1-\mathrm{X}_{\mathrm{EGR}}\right)<\mathrm{m}_{\mathrm{d} 0} /(1-0)\left(\mathrm{m}_{\mathrm{d}}=\mathrm{m}_{\mathrm{d} 0} \text { at } \mathrm{X}_{\mathrm{EGR}}=0\right)
$$

then,

$$
\mathrm{m}_{\mathrm{d}} / \mathrm{m}_{\mathrm{d} 0}<\left(1-\mathrm{X}_{\mathrm{EGR}}\right)
$$

Figure 17 shows change due to the EGR ratio in the normalized diffusion combustion mass $\mathrm{m}_{\mathrm{d}} / \mathrm{m}_{\mathrm{d} 0}$. The right hand side of Eq.(2) corresponds to the thick solid line with its gradient of (-1). If the value of $\mathrm{m}_{\mathrm{d}} / \mathrm{m}_{\mathrm{d} 0}$ locates in the region below the thick solid line, the PM can be reduced by EGR. The experimental data shown in Fig.17 are identical to the ones shown in Fig.6. Only in the case of $50 \%$ ethanol blend fuel EtOH50, PM could be reduced by increasing the EGR ratio, and NOx, of course, could be reduced simultaneously by EGR.

\subsection{Improved Results of PM-NOx Trade-off}

Figure 18 shows the relation between the $50 \%$ burnt point CA50 and the EGR ratio in the case of the $50 \%$ ethanol blend fuel EtOH50. The CA50 was defined as the crank angle at which the cumulative heat release becomes $50 \%$. At the fuel injection timing of 5 deg.CA BTDC, the EGR ratio was limited up to 0.2 due to misfire as shown in Fig.11, on the other hand, the EGR 
ratio for the misfire limit was 0.38 at $\mathrm{p}_{\mathrm{me}}=0.51 \mathrm{MPa}$ at the fuel injection timing of 14 deg.CA BTDC. The figure indicates that misfire occurs if the CA50 reaches between 10 and 15 deg.CA ATDC, which is seen not only in the present case but also in the HCCI engine ${ }^{[12]}$. In order to achieve less NOx, the EGR ratio should be increased more. If the fuel injection timing is advanced from 5 to 14 deg.CA BTDC, a high EGR ratio is allowable for the misfire limit.

Figure 19 shows the PM-NOx trade-off lines in the cases of gas oil and EtOH50. The ordinate denotes the specific particulate matter $\mathrm{PM} \mathrm{g/kWh}$ and the abscissa denotes the specific emission of NOx g/kWh. As shown in Fig.19, the original trade-off based on gas oil, showing high levels of PM and NOx, is drastically improved by means of the $50 \%$ ethanol blend fuel EtOH50. By adopting the allowable highest EGR ratio in the case of EtOH50 having low cetane number and low evaporation temperature, both NOx and PM was reduced simultaneously below the post new-long term emission standards for 2009 in Japan. Very low levels of $0.4 \mathrm{~g} / \mathrm{kWh}$ in NOx and $0.006 \mathrm{~g} / \mathrm{kWh}$ in PM could be achieved at the fuel injection timing of $14 \mathrm{deg}$.CA BTDC without deterioration of thermal efficiency, which are really achieved by promotion of the premixing.

\section{CONCLUSION}

The goal of the present study is to show one of the approaches for achieving low NOx and low PM combustion in a diesel engine by utilizing bio-ethanol and adopting EGR. The gas oil was blended with bio-ethanol for realizing a PCI engine in the present experiment. The concluding remarks obtained here are as follows;

(1) Ignition delay increases with increase in the ethanol blend ratio, and also increases more by increasing the EGR ratio, resulting in promotion of the premixing.

(2) A marked increase in ignition delay due to ethanol blending is based on low cetane number, low evaporation temperature and large latent heat of ethanol.

(3) Increase in ignition delay due to EGR is caused by the so-called dilution effect with the low oxygen charge.

(4) Increase in the ethanol blend ratio promotes the premixing, and results in a decrease in the diffusion combustion quantity.

(5) It is found that PM is a function of $m_{d} /\left(1-X_{E G R}\right)$ alone; where $m_{d}$ is the mass rate of diffusion combustion and $\mathrm{X}_{\mathrm{EGR}}$ is the EGR ratio. Furthermore $\mathrm{m}_{\mathrm{d}}$ is dominated by the injection quantity of gas oil.

(6) It is noticed that, in the case of the $50 \%$ ethanol blend fuel, PM could be reduced by increasing the EGR ratio due to a remarkable increase in ignition delay.

(7) Very low levels of NOx and PM could be achieved without deterioration of the thermal efficiency by promotion of the premixing.

\section{ACKNOWLEDGEMENTS}

The authors express their gratitude to the engineers of Yanmar Co., Ltd. for their supports, and also wish to thank to Mr. Nishijima, K., et al, graduate students in Energy System Laboratory, Nagasaki University. 


\section{REFERENCES}

[1] Kusaka, J. et al., "Combustion and Exhaust Gas Emissions Characteristics of a Diesel Engine Dual-Fueled with Natural Gas", Proc. 4th COMODIA , Kyoto (1998), pp.555-560

[2] Ishida, M., Tagai, T and Ueki, H., "Effect of EGR and Preheating on Natural Gas Combustion Assisted with Gas-Oil in a Diesel Engine“, JSME International Journal, Series B, Vol.46, No.1 (2003), pp.124-130

[3] Tagai, T., Ishida, M., Ueki, H. and Watanabe, T., "Effect of Equivalence Ratio and Temperature of CNG Premixture on Knock Limit in a Dual Fueled Diesel Engine", SAE 2003 Transactions, Journal of Fuels and Lubricants (2003), pp.1807-1816

[4] Saito, H., Sakurai, T., Sakonji, T., Hirashima, T. and Kanno, K., "Study on Lean Burn Gas Engine Using Pilot Oil as the Ignition Source", SAE (2001), Paper No.2001-01-0143

[5] Carlucci, A. P., De Risi, A., Laforgia, D. And Naccarato, F., "Experimental investigation and combustion analysis of a direct injection dual-fuel diesel-natural gas engine", Energy 33 (2008) pp.256-263

[6] Papagiannakis, R. G., Kotsiopoulos, P. N., Zannis, T. C., Yfantis, E. A., Hountalas, D. T. And Rakopoulos, C. D., "Theoretical study of the effects of engine parameters on performance and emissions of a pilot ignited natural gas diesel engine", Energy 35 (2010), pp.1129-1138

[7] Ishida, M., Ueki, H., Sakaguchi, D. and Imaji, H., "Simultaneous Reduction of NOx and Smoke by Port Injection of Methanol/Water Blend in a DI Diesel Engine", Proc. 15th ICE Symposium (International), Seoul, Paper No.9935202 (1999), pp.93-98

[8] Ishida, M., Tagai, T., Ueki, H. and Sakaguchi, D., "Ignition and Combustion Characteristics of Methanol Mixture in a Dual Fuel Diesel Engine", Proc. 6th COMODIA, Yokohama (2004), pp. 1-8

[9] Ishida, M., Tagai, T., Ueki, H. and Sakaguchi, D., "Comparison of Combustion Characteristics between Natural Gas and Methanol in a Dual Fuel Diesel Engine“, Proc. International Conference VAFSEP, Dublin (2004), pp.217-222

[10] Kajitani, S., Chen, Z. L., Konno, M. and Rhee, K. T., "Engine Performance and Exhaust Characteristics of Direct Injection Diesel Engine Operated with DME", SAE (1997), Paper No.972973

[11] Kajitani, S., Oguma, M. and Mori, T., "DME Fuel Blends for Low-emission, Directinjection Diesel engines", SAE (2000), Paper No.2000-01-2004

[12] Ohmura, T., Ikemoto, M. and Iida, N., "A Study on Combustion Control by Using Internal and External EGR for HCCI Engines Fuelled with DME", 2006 SAE Transactions, Journal of Engines (2006), pp.1043-1052

[13] Chen, Z., Konno, M., Oguma, M. and Yanai, T., "Experimental Study of CI Natural Gas/DME Homogeneous Charge Engine", SAE (2000), Paper No.2000-01-0329

[14] Chen, Z., and Konno, M., "How to Put the HCCI Engine to Practical Use: Control the Ignition Timing by Compression Ratio and Increase the Power Output by Supercharge", SAE 2003 Transactions, Journal of Fuels and Lubricants (2003), pp.1255-1263

[15] Konno, M. and Chen, Z., "Ignition Mechanisms of HCCI Combustion Process Fuelled with Methane/DME Composite Fuel", SAE (2005), Paper No. 2005-01-0182

[16] Iida, N. et al., "Basic Research on the Suitable Fuel for HCCI Engine from the Viewpoint of Chemical Reaction", SAE (2005), Paper No. 2005-01-0149

[17] Ishida, M., Jung, S., Ueki, H. and Sakaguchi, D., "Combustion of Premixed DME and Natural Gas in a HCCI Engine", Polish Journal of Combustion Engines (PTNSS2005), Nr.2/2005 (121) (2005), pp.20-29 
[18] Ishida, M., Jung, S., Ueki, H. and Sakaguchi, D., "Effect of Exhaust Gas Recirculation on Combustion in a HCCI Engine Fuelled with DME/Natural Gas", International Conference $2^{\text {nd }}$ VAFSEP (2006), Paper No.133, pp.61-66

[19] Ishida, M., Jung, S., Ueki, H. and Sakaguchi, D., "Combustion Characteristics of HCCI Engines Fuelled with Natural Gas and DME", $25^{\text {th }}$ CIMAC (2007), Paper No.171, CD-ROM (15 Pages)

[20] Ishida, M., Jung, S. H., Ueki, H. and Sakaguchi, D., "Experimental analysis of thermal efficiency improvement due to high EGR ratio in HCCI engines fuelled with DME and Natural gas", COMODIA (2008), pp.289-296

[21] Jung, S. H., Ishida, M., Ueki, H. and Sakaguchi, D., "Ignition Characteristics of Methanol and Natural-Gas in a HCCI Engine Assisted by DME", 2007 JSAE/SAE International Fuels and Lubricants Meeting (2007), SAE Paper No.2007-01-1863, pp.1-6

[22] Ganesh, D. and Nagarajian, G., "Homogeneous charge compression ignition (HCCI) combustion of diesel fuel with external mixture formation", Energy 35 (2010), pp.148-157

[23] García, M. T., Aguilar, F. J. J. and Lencero, T. S., "Experimental study of the performances of a modified diesel engine operating in homogeneous charge compression ignition (HCCI) combustion mode versus the original diesel combustion mode", Energy 34 (2009), pp.159-171

[24] Shudo, T. and Ono, Y., "HCCI Combustion of Hydrogen, Monoxide and Dimethyl Ether", SAE 2002 Transactions, Journal of Engines (2002), pp.459-464

[25] Shudo, T., Ono, Y. and Takahashi, T., "Influence of Hydrogen and Carbon Monoxide on HCCI Combustion of Dimethyl Ether", SAE 2002 Transactions, Journal of Fuels and Lubricants (2002), pp.1784-1793

[26] Tsolakis, A., Megaritis, A. and Yap, D., "Application of exhaust gas fuel reforming in diesel and homogeneous charge compression ignition (HCCI) engines fuelled with biofuels", Energy 33(2008), pp.462-470

[27] Ogawa, H., Li, T., Miyamoto, N., Kido, S. and Shimizu, H., "Dependence of Ultra-High EGR and Low Temperature Diesel Combustion on Fuel Injection Conditions and Compression Ratio", SAE (2006), Paper No.2006-01-3386

[28] Li, T., Izumi, H., Shudo, T., Ogawa, H. and Okabe, Y., "Characterization of Low Temperature Diesel Combustion with Various Dilution Gases”, SAE (2007), Paper No. 200701-0126

[29] Li, T., Suzuki, M. and Ogawa, H., "Effects of In-Cylinder Temperature and Fuel-Air Mixing on Smokeless Low Temperature Diesel Combustion”, COMODIA (2008) Paper No. DE1-1, pp.135-142

[30] Ishida, M., Tagai, T. and Ueki, H., "Effects of Gasoline/Gas-Oil Blend on Smoke Reduction in a Diesel Engine", Reports of the Faculty of Engineering, Nagasaki University, Vol.34, No.63 (2004), pp.9-15 (in Japanese)

[31] Kamio, J., Kurotani, T., Kuzuoka, K., Kubo, Y., Taniguchi, H. And Hashimoto, K., "Study on HCCI-SI Combustion Using Fuels Containing Ethanol”, SAE (2007) Paper No. 2007-014051

[32] Megaritis, A., Yap, D. and Wyszynski, M. L., "Effect of water blending on bioethanol HCCI combustion with forced induction and residual gas trapping", Energy 32 (2007), pp.2396-2400

[33] Mack, J. H., Aceves, S. M. and Dibble, R. W., "Demonstrationg direct use of wet ethanol in a homogeneous charge compression ignition (HCCI) engine", Energy 34 (2009), pp.782-787

[34] Rakopoulos, C. D., Antonopoulos, K. A. and Rakopoulos, D. C., "Experimental heat release analysis and emissions of a HSDI diesel engine fueled with ethanol-diesel fuel blends", Energy 32 (2007), pp.1791-1808 
[35] Miyamoto, N., Chikahisa, T., Murayama, T. And Sawyer, R., "Description and Analysis of Diesel Engine Rate of Combustion and Performance Using Wiebe's Functions", SAE (1985), Paper No.850107

[36] Ishida, M., Ueki, H., Matsumura, N., Yamaguchi, M. and Luo, G., "Diesel Combustion Analysis Based on Two-Zone Model (Comparison between Model Analysis and Experiment)", JSME International Journal, Series B, Vol.39, No.1 (1996), pp.185-192

[37] Ishida, M., Ueki, H., Matsumura and Chen, Z., "Diesel Combustion Analysis Based on Two-Zone Model (Examination of Excess Air Ratio in Burned Zone)", JSME International Journal, Series B, Vol.39, No.3 (1996), pp.632-639 
Table 1 Principal particulars of test engine

\begin{tabular}{ll} 
Model type & NFD-170(E), Single cylinder, \\
& Water-cooled, Four-stroke \\
Bore and stroke & $102 \times 105[\mathrm{~mm}]$ \\
Compression ratio & 17.8 \\
Maximum power and speed & $12.5[\mathrm{KW}] / 2,400[\mathrm{rpm}]$ \\
Valve timing & Opening $\quad$ Closing \\
$\quad$ Intake & $8\left[{ }^{\circ} \mathrm{BTDC}\right] \quad 40\left[{ }^{\circ} \mathrm{ABDC}\right]$ \\
$\quad$ Exhaust & $50\left[{ }^{\circ} \mathrm{BBDC}\right] \quad 12\left[{ }^{\circ} \mathrm{ATDC}\right]$ \\
Fuel pump & Bosch PFR-1AW with $9 \mathrm{~mm}$ plunger \\
Injection nozzle & 4 holes with 0.29 dia. $[\mathrm{mm}]$ \\
Opening pressure & $19.6[\mathrm{MPa}]$ \\
\hline
\end{tabular}

Table 2 Combustion test conditions

\begin{tabular}{ll}
\hline Engine speed & $1,200 \mathrm{rpm}$ \\
Suction air pressure & $0.1013 \mathrm{MPa}$ \\
Intake air temperature & $40{ }^{\circ} \mathrm{C}$ \\
Injection timing & 5,14 deg.CA BTDC \\
Mean effective pressure; $\mathrm{p}_{\mathrm{me}}$ & $0.13(20 \%)-0.51(80 \%) \mathrm{MPa}$ \\
EGR ratio; $\mathrm{X}_{\mathrm{EGR}}$ & $0-0.5$ or misfire limit \\
\hline
\end{tabular}

Table 3 Properties of test fuels

\begin{tabular}{|c|c|c|c|c|}
\hline & Gas oil & EtOH30 & EtOH50 & Ethanol \\
\hline Gas oil [vol\%] & 100 & 68 & 48 & 0 \\
\hline Ethanol [vol\%] & 0 & 29 & 48 & 100 \\
\hline Octanol [vol\%] & 0 & 3 & 4 & 0 \\
\hline $\begin{array}{c}\text { Lower heating value } \\
{[\mathrm{MJ} / \mathrm{kg}]}\end{array}$ & 42.9 & 38.3 & 35.2 & 26.8 \\
\hline $\begin{array}{c}\text { Latent heat } \\
{[\mathrm{MJ} / \mathrm{kg}]}\end{array}$ & 0.25 & 0.43 & 0.55 & 0.86 \\
\hline Boiling point [ $\left.{ }^{\circ} \mathrm{C}\right]$ & $190-350$ & - & - & 78.3 \\
\hline Oxygen [w\% $\%]$ & 0 & 10.1 & 16.8 & 34.8 \\
\hline Cetane No. & 55 & 41 & 32 & 8 \\
\hline
\end{tabular}


Table 4 Summary of equipment, detection principle, andaccuracy of measurements

\begin{tabular}{|l|l|l|l|l|}
\hline Measuring item & Detection principle & Equipment (Maker) & Scale range & Accuracy \\
\hline $\mathrm{CO}$ & Constant potential electrolysis & testo350M (TESTO) & $0-10000[\mathrm{ppm}]$ & $\pm 5 \%$ Linearity \\
\hline NOx & $\begin{array}{l}\text { CLD (chemical luminescence } \\
\text { detector) }\end{array}$ & ECL-77A (Yanaco) & $0-1000[\mathrm{ppm}]$ & $\pm 1 \% \mathrm{FS}$ \\
\hline THC & FID (flame ionization detector) & EHF-710H (Yanaco) & $0-1000[\mathrm{ppm}]$ & $\pm 1 \% \mathrm{FS}$ \\
\hline Smoke & Bosch type & DSM-10 (BANZAI) & $0-10[\mathrm{Bosch}]$ & $\pm 2 \%$ Linearity \\
\hline $\mathrm{CO}_{2}$ & NDIR(non-dispersive infrared) & BIR-200 (BEST SOKKI) & - & $\pm 1 \% \mathrm{FS}$ \\
\hline $\begin{array}{l}\text { In-cylinder } \\
\text { pressure }\end{array}$ & $\begin{array}{l}\text { Piezoelectric transducer/ } \\
\text { charge amplifier }\end{array}$ & $6125 \mathrm{~B} / 5011 \mathrm{~B}$ (KISTLER) & $0-250[\mathrm{bar}]$ & $\pm 0.5 \% \mathrm{FS}$ \\
\hline Needle valve lift & Gap sensor & PU-03A (AEC) & $0-1[\mathrm{~mm}]$ & $0.3[\mu \mathrm{m}]$ \\
\hline Crank angle & Encoder & PP-011A (Ono Sokki) & - & $\pm 0.25 \mathrm{deg}$ \\
\hline $\begin{array}{l}\text { Torque } \\
\text { Torque detector/meter }\end{array}$ & $\begin{array}{l}\text { DSTP-10/ DMT-408 } \\
\text { (Ono Sokki) }\end{array}$ & $0-100[\mathrm{Nm}]$ & $\pm 0.5 \% \mathrm{FS}$ \\
\hline Temperature & Thermo-couple & E type/T type (YAMARI) & $0-900 / 0-350\left[{ }^{\circ} \mathrm{C}\right]$ & $\pm 1.7 / \pm 1.0\left[{ }^{\circ} \mathrm{C}\right]$ \\
\hline Fuel flow rate & Electronic weighing & EB-32KD (SHIMADZU) & $0-32[\mathrm{~kg}]$ & $\pm 1[\mathrm{~g}]$ \\
\hline Air flow rate & Inlet nozzle pressure drop & ISP-3-50 (SHIBATA) & $0-50[\mathrm{mmAq}]$ & $\pm 1 \% \mathrm{FS}$ \\
\hline
\end{tabular}




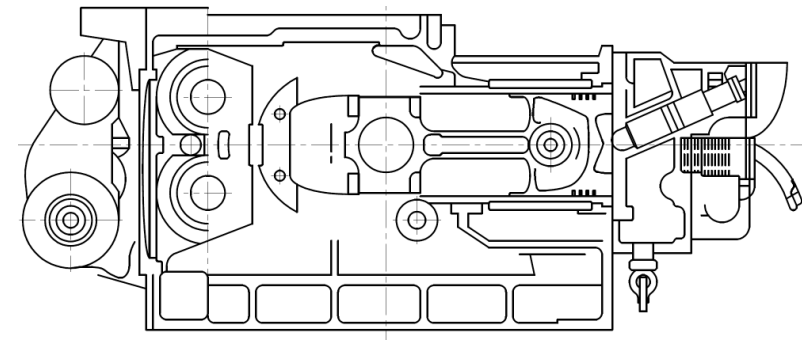

(a) Section of test engine

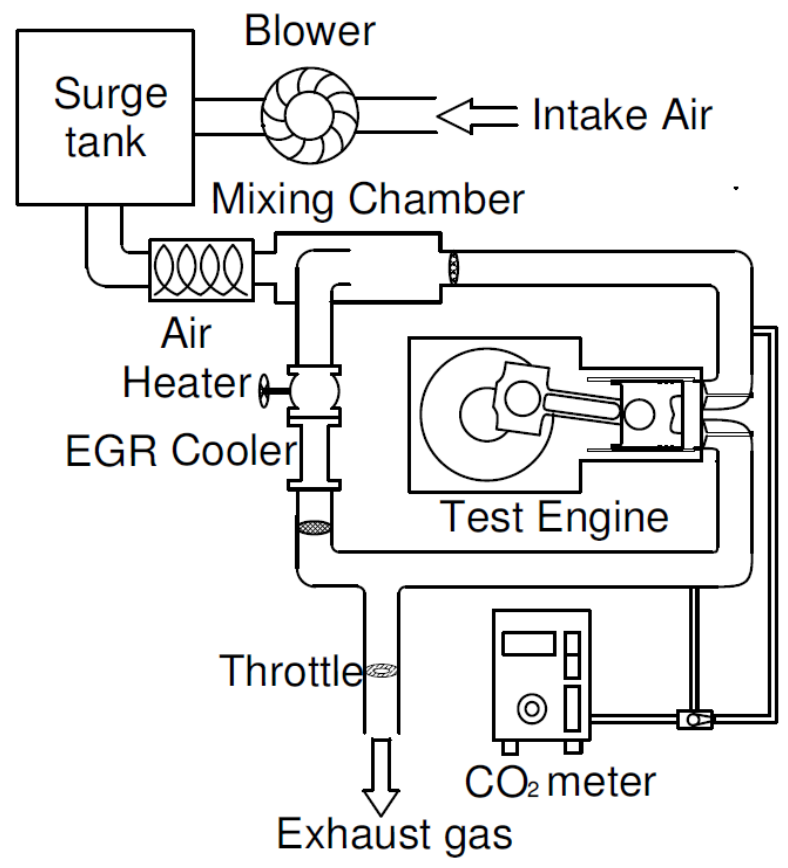

(b) Combustion test system

Fig.1 Test engine and combustion test system

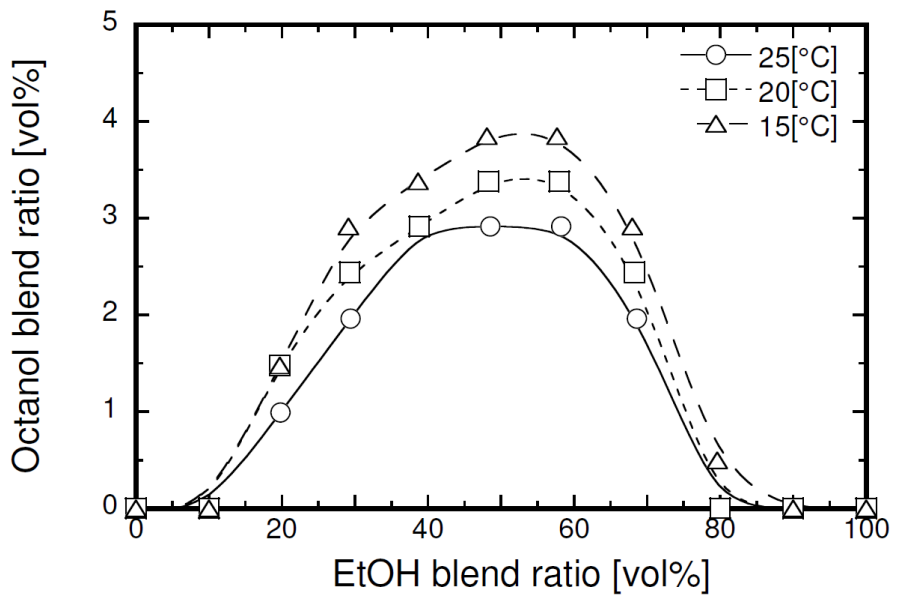

Fig.2 Effect of octanol on solubility between gas oil and ethanol 

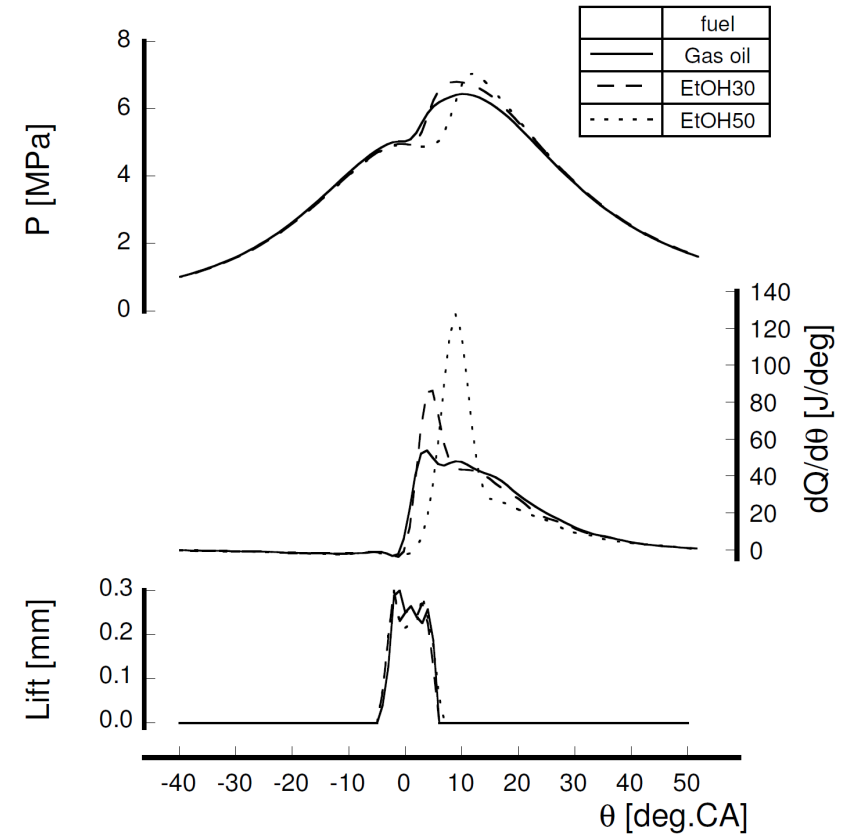

(a) Effect of ethanol blend ratio $\left(\mathrm{p}_{\mathrm{me}}=0.51[\mathrm{MPa}]\right)$

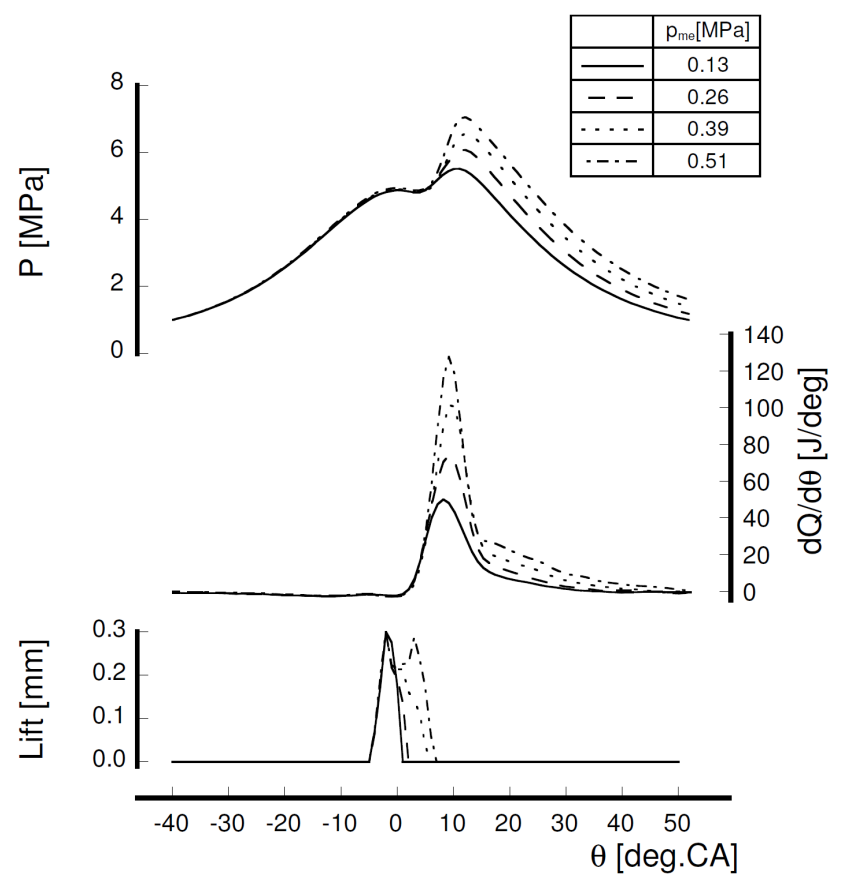

(b) Effect of engine load (EtOH50)

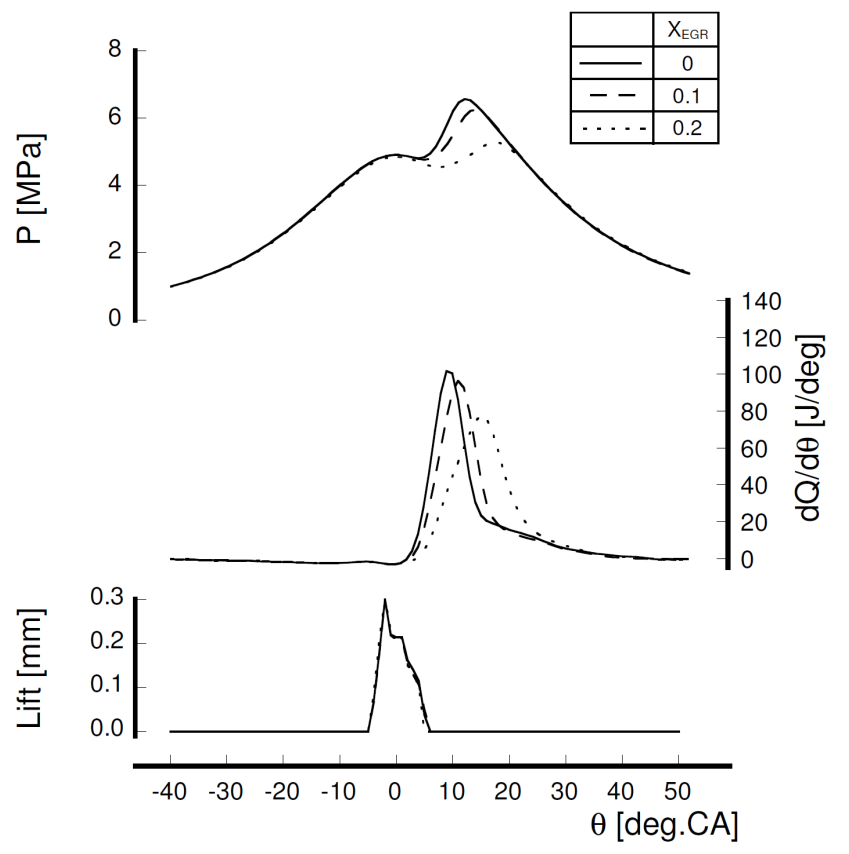

(c) Effect of EGR ratio (EtOH50, $\left.\mathrm{p}_{\mathrm{me}}=0.39[\mathrm{MPa}]\right)$

Fig. 3 Change in combustion time-history 


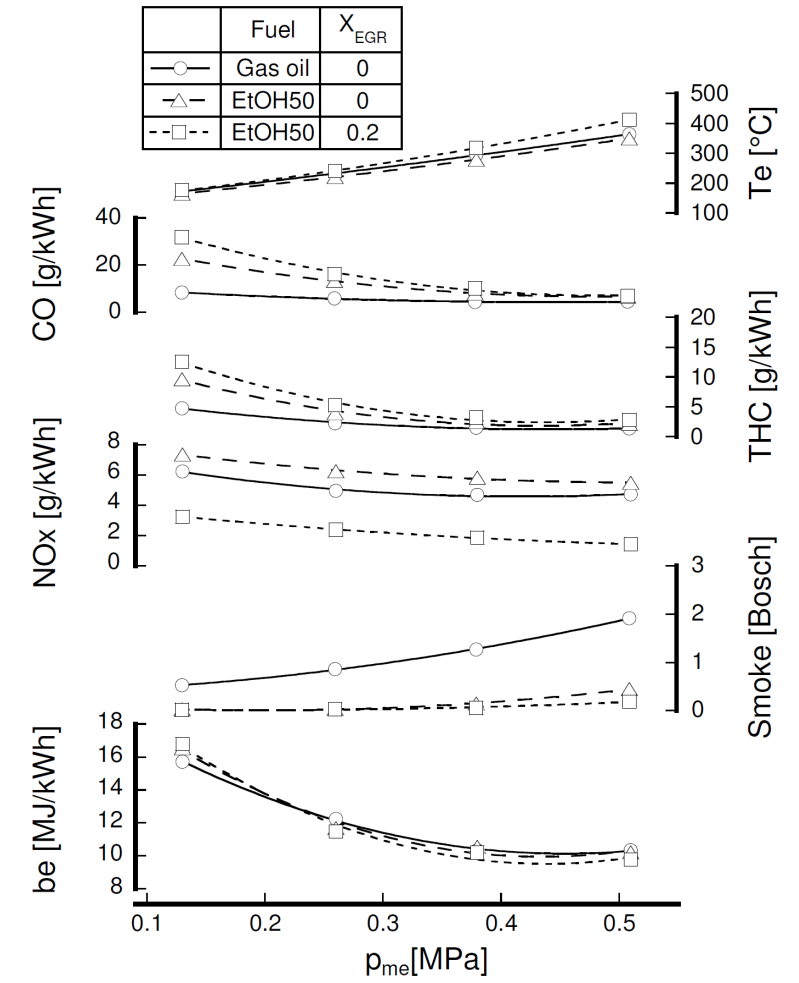

Fig.4 Effects of ethanol and EGR on exhaust emissions and engine performance

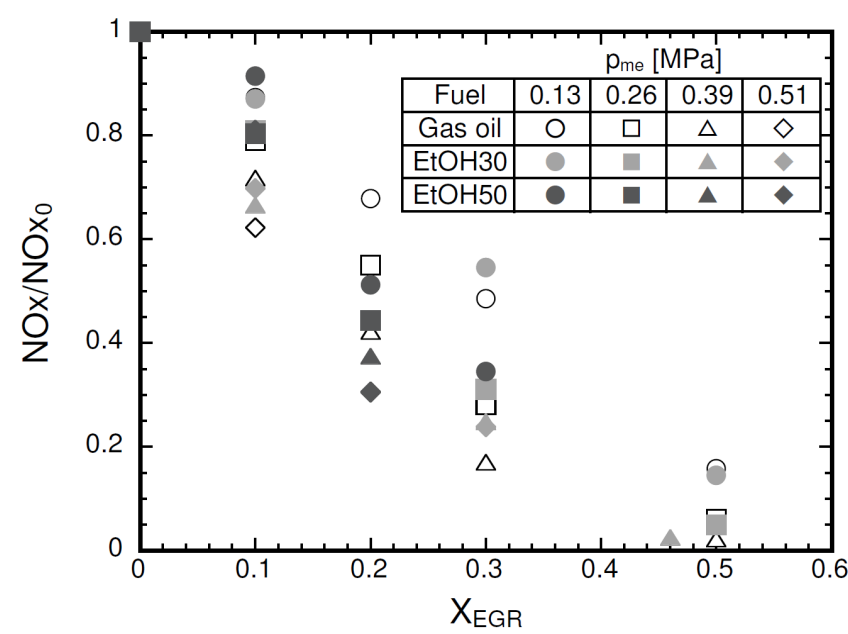

Fig.5 NOx reduction rate due to EGR

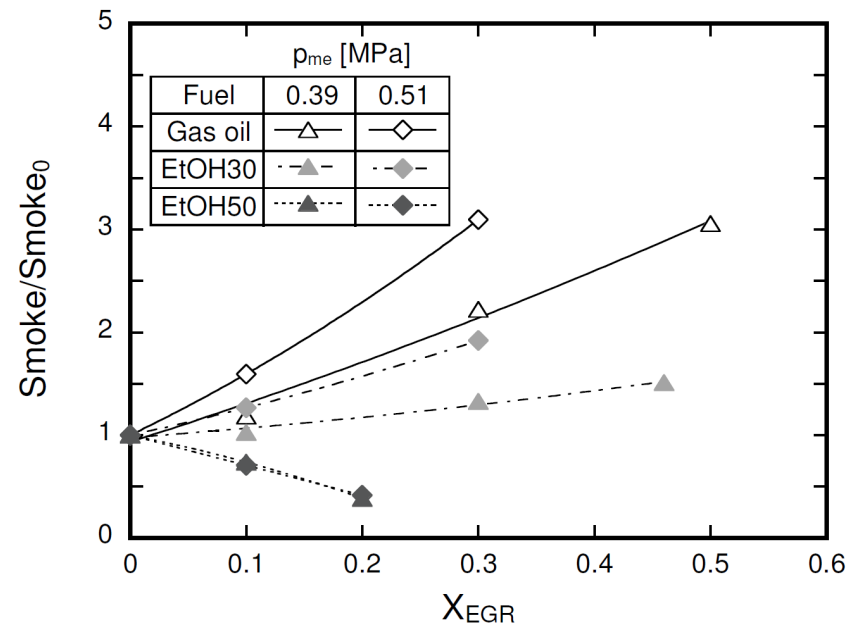

Fig.6 Change in smoke due to EGR

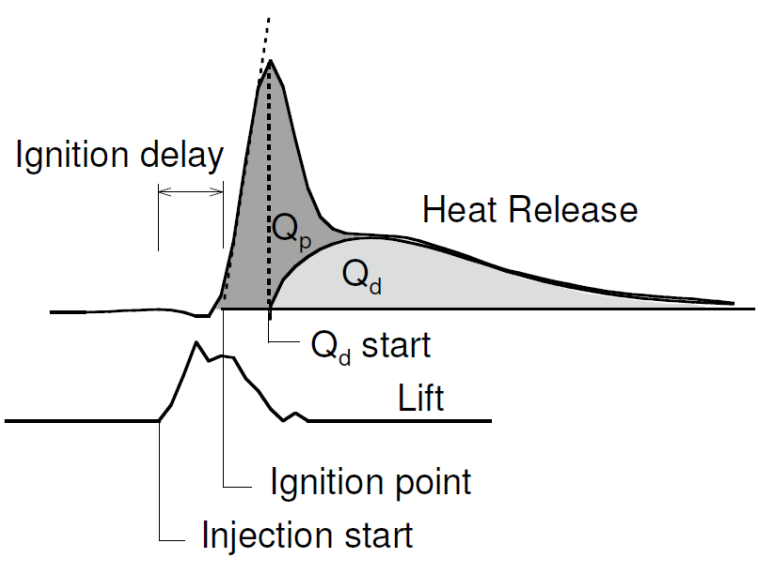

Fig.7 Definitions of ignition delay, premixed combustion $\mathrm{Q}_{\mathrm{p}}$ and diffusion combustion $\mathrm{Q}_{\mathrm{d}}$

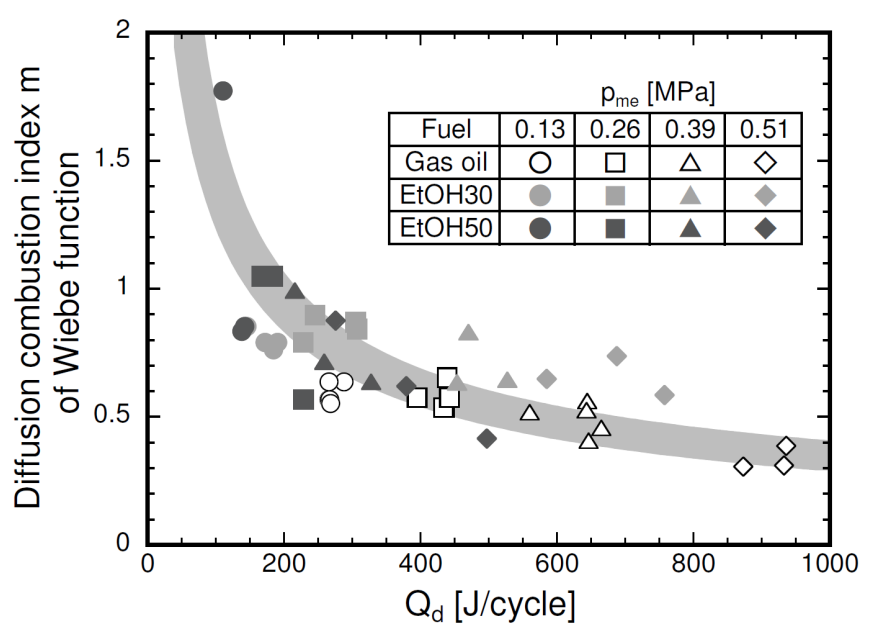

Fig.8 Uncertainty of diffusion combustion index " $m$ " approximated by Wiebe function 


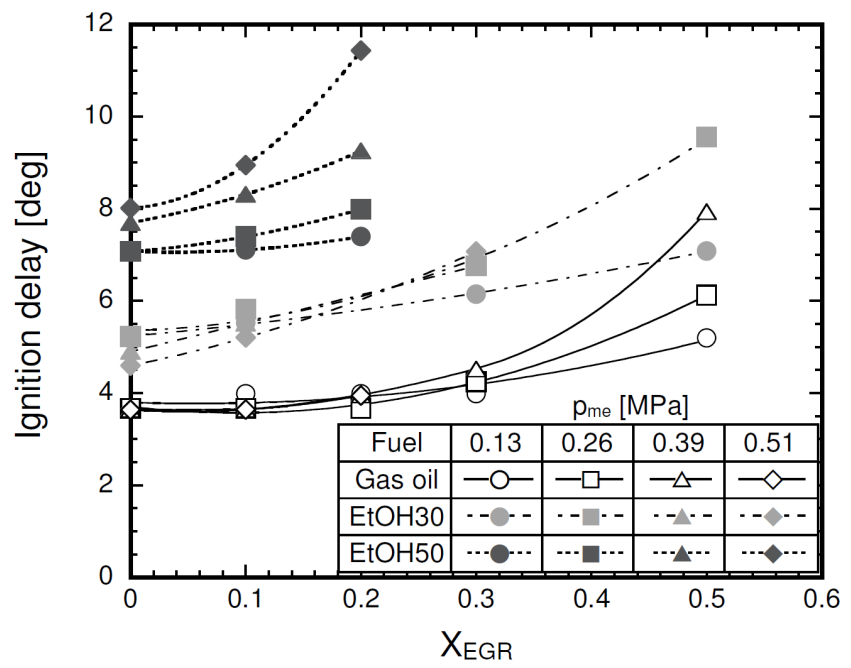

Fig.9 Effects of ethanol and EGR on ignition delay

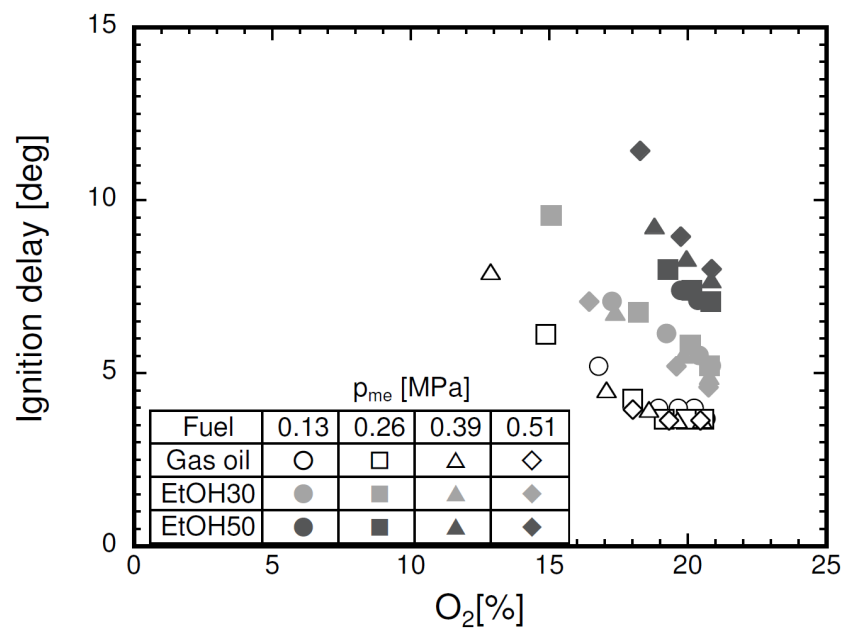

Fig. 10 Change in ignition delay due to oxygen concentration in intake charge

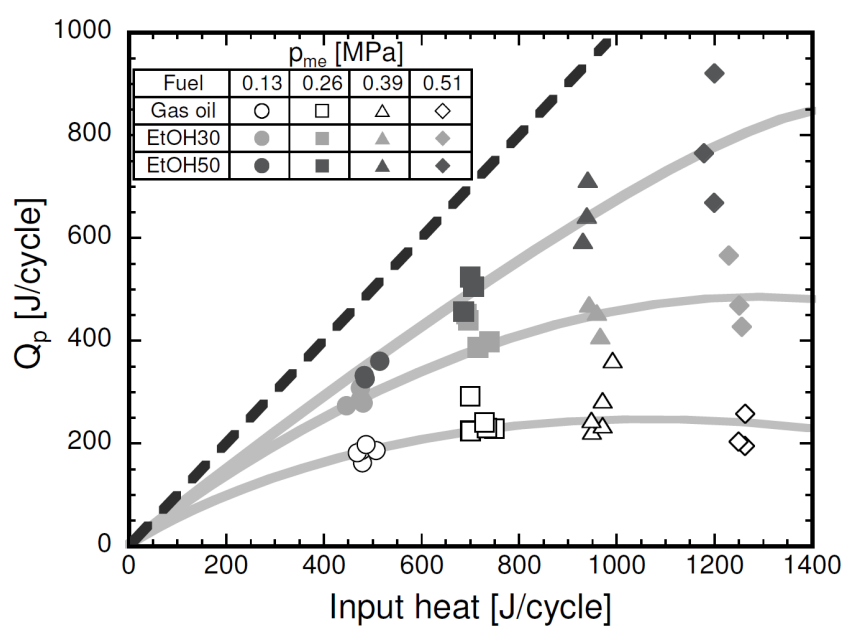

(a) $Q_{p}$ vs total amount of input heat

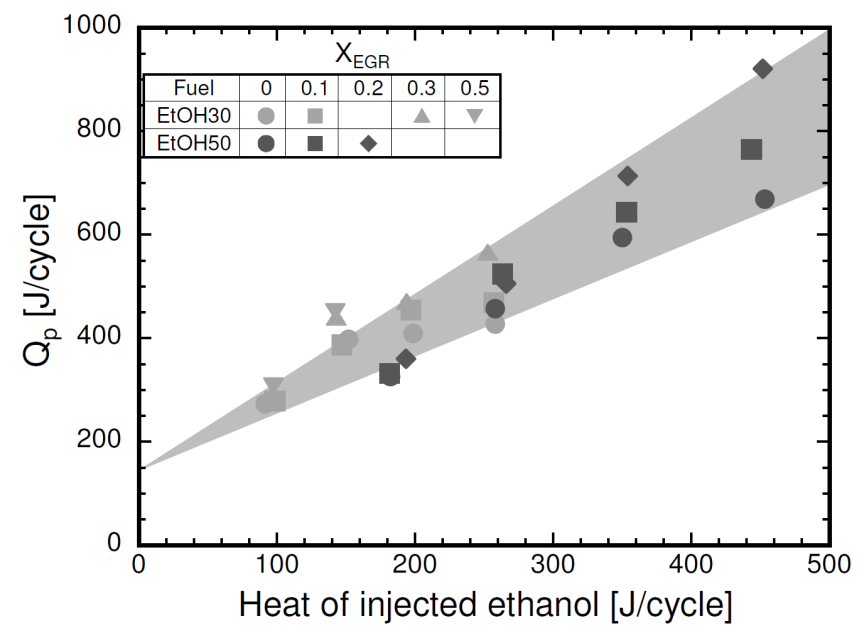

(b) $Q_{p}$ vs amount of injected ethanol heat

Fig.11 Relationship between premixed combustion

$\mathrm{Q}_{\mathrm{p}}$ and amount of heat input 


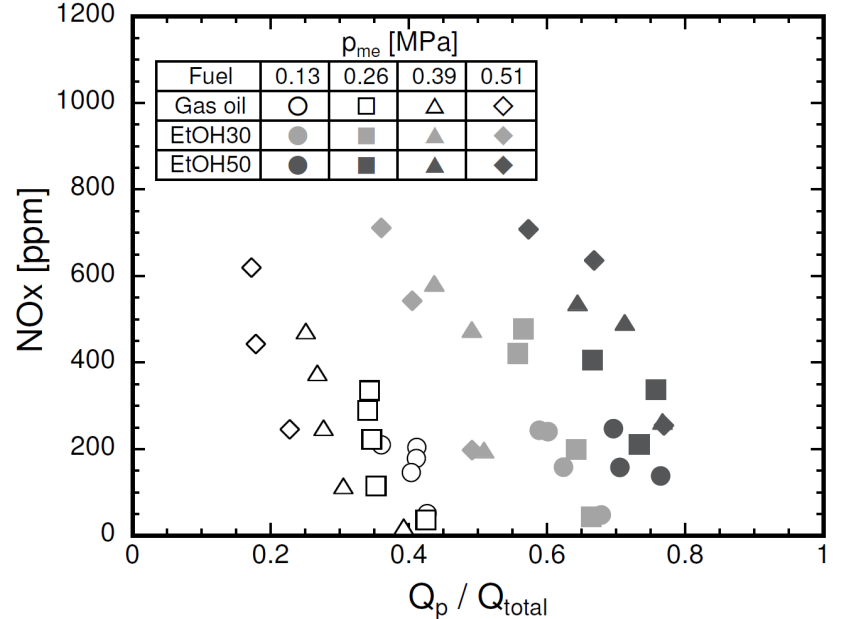

Fig.12 Effect of $\mathrm{Q}_{\mathrm{p}} / \mathrm{Q}_{\text {total }}$ on NOx

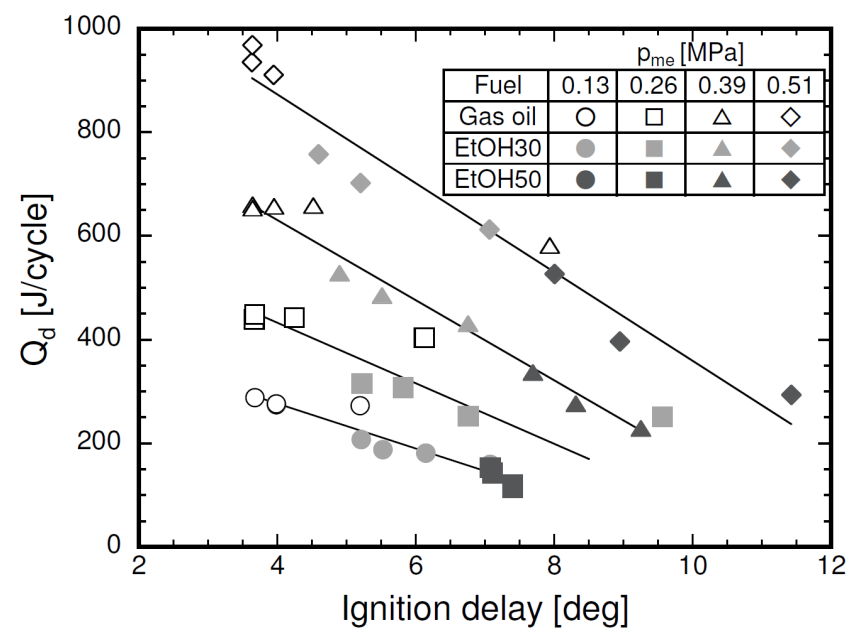

Fig.13 Change in cumulative heat release during diffusion combustion $\mathrm{Q}_{\mathrm{d}}$ due to ignition delay

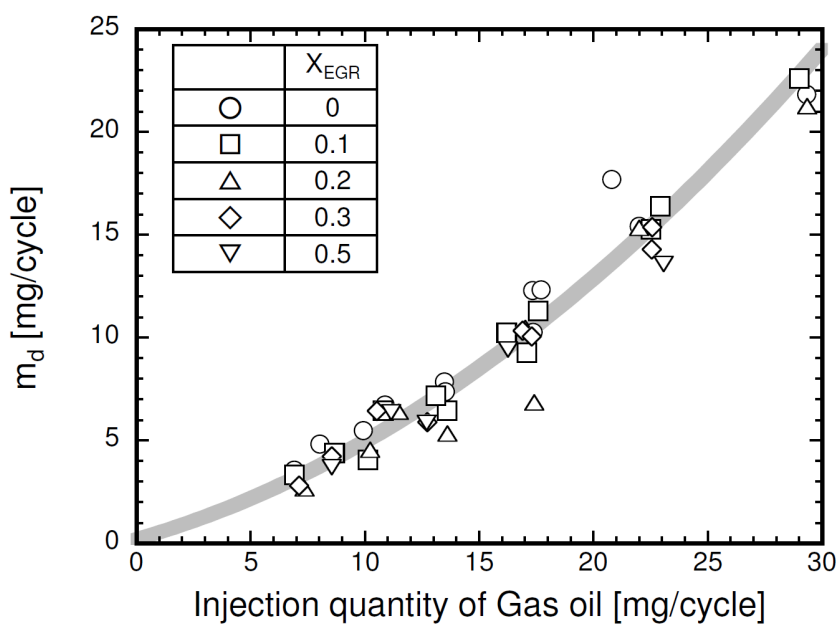

Fig.14 Correlation between diffusion combustion mass and injected amount of gas oil

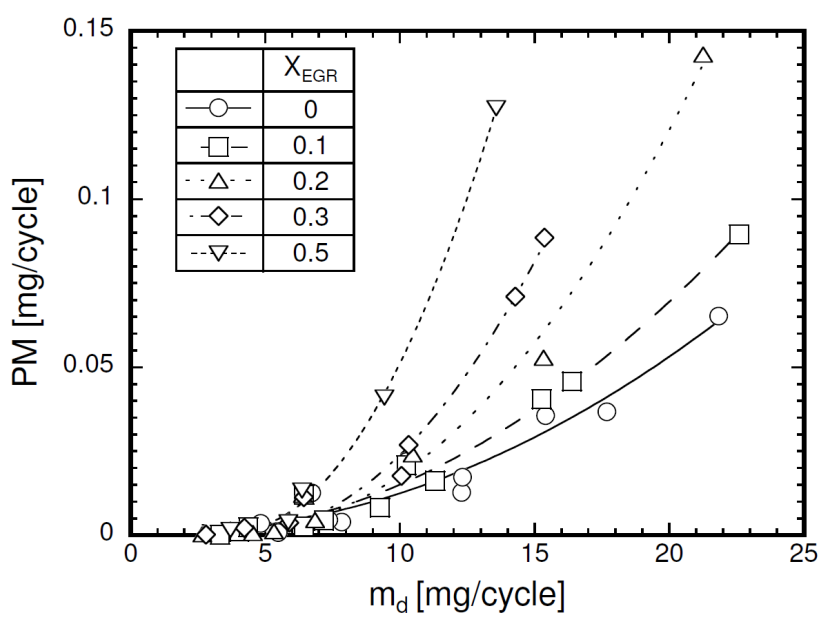

Fig.15 Relationship between PM, diffusion combustion mass $\mathrm{m}_{\mathrm{d}}$ and EGR ratio $\mathrm{X}_{\mathrm{EGR}}$

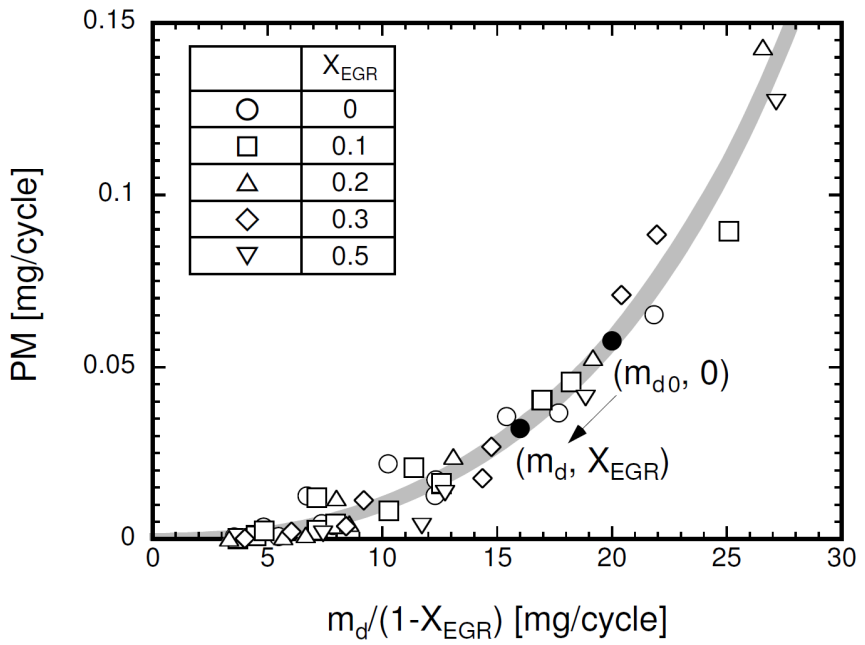

Fig. 16 Correlation between $\mathrm{PM}$ and $\mathrm{m}_{\mathrm{d}} /\left(1-\mathrm{X}_{\mathrm{EGR}}\right)$

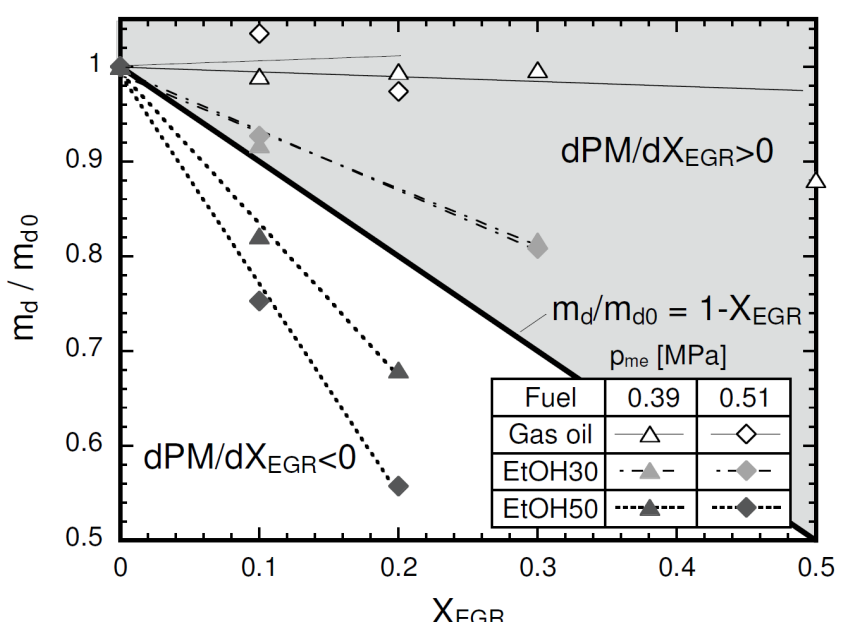

Fig.17 Change in normalized diffusion combustion mass $m_{d} / m_{d 0}$ due to EGR 


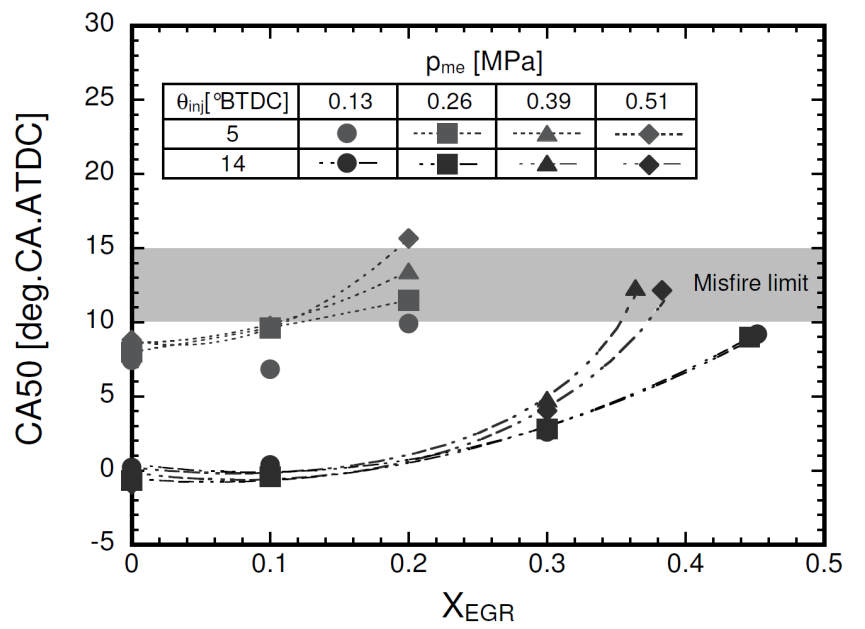

Fig. 18 Change in $50 \%$ burnt point CA50 due to EGR

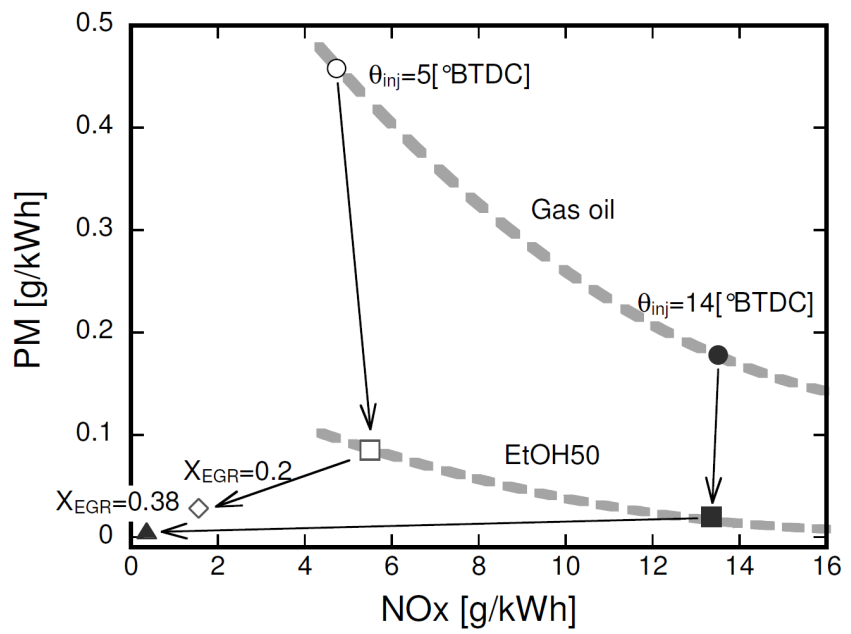

Fig. 19 Improvement in PM-NOx trade-off due to ethanol blend and EGR 